\title{
A inglória ilha de Gloriana: Elizabeth I, responsabilidade e honra na Guerra dos Nove Anos na Irlanda ${ }^{1}$
}

Gloriana's Inglorious Island: Elizabeth I, responsibility and honour in the Nine Years War in Ireland

Eoin O’Neill ${ }^{\star}$

Tradução: Irene C. M. H. M. Portela

\section{Resumo}

Elizabeth I, também conhecida como Gloriana, é personagem de fama duradoura, tanto na historiografia popular como na comunidade acadêmica. Diferentemente do que ocorreu na Inglaterra, o seu legado na Irlanda é assunto complexo e longe de glorioso. Boa parte dessa herança está ligada à Guerra dos Nove Anos, que dominou a década final de seu reinado. Neste artigo, detenho-me em dois aspectos que permitem lançar luz sobre o papel de Elizabeth: primeiro, a responsabilidade pelo deflagrar da guerra em si e, em segundo lugar, a influência que teve e o modo como interferiu na sua condução.

Palavras-chave: Irlanda; Guerra dos Nove Anos (1594-1603); Elizabeth I.

\section{Abstract}

Elizabeth I still enjoys a very positive reputation, both in popular history and in the academic community. Unlike in England, her legacy in Ireland is very complex and far from glorious. Much of this legacy is related to the Nine Years War, which dominated the final decade of Elizabeth's reign. In this article I will focus on two aspects, in order to highlight Elizabeth's contribution to the war: first, her responsibility for the war itself, and second, her influence and interference in the waging of the war.

Keywords: Ireland; Nine Years War (1594-1603); Elizabeth I.

Há tempos Elizabeth I desfruta de excelente reputação. Isso aplica-se tanto aos retratos populares da "Good Queen Bess" e de Gloriana na mídia como à maior parte dos trabalhos históricos que lidam com ela. A imagem positiva é ainda mais forte na academia. Na introdução a um dos poucos trabalhos relativos ao "lado negro" de Elizabeth, a editora, Julia Walker, descreve as dificuldades que teve em atrair artigos sobre o assunto e atribui-as à "recorrente

\footnotetext{
* Pós-doutor pelo Programa de Pós-Graduação em História, Universidade Federal Fluminense (UFF). eoneill@oi.com.br
} 
popularidade de Elizabeth" (Walker, 1998, p.1-2). Não obstante, qualquer pessoa em busca de material sobre o "lado negro" de Elizabeth não terá dificuldade em encontrá-lo na Irlanda, especialmente se considerar a última década de seu reinado. É com isso que o presente trabalho lida.

$\mathrm{Na}$ Inglaterra, o período elisabetano é visto como uma espécie de era dourada. Na Irlanda, o legado de Elizabeth é muito mais complicado e tem sido objeto de debates. Ao invés de uma era dourada, o que houve foram numerosas guerras e rebeliões, com frequência aniquiladas de maneira brutal. Lei marcial e táticas de terra arrasada foram amplamente utilizadas - com sua corte de horrores. Cabe também considerar que Elizabeth foi, em última análise, responsável por essas guerras e pelo que nelas ocorreu. A sua política com relação à Irlanda era inconstante e, frequentemente, negligente (muito embora caiba perguntar se poderia ter sido diferente). Na verdade, se houve qualquer consistência da parte dela em relação à Irlanda foi no desejo de ter de lidar e de gastar o mínimo possível com a ilha. Infelizmente para ela, foi obrigada a se ocupar cada vez mais da Irlanda à medida que esta se tornava o principal problema que precisou enfrentar nos últimos anos de seu reinado.

A relutância de Elizabeth em lidar com a Irlanda, bem como em definir e seguir uma política coerente em relação ao país, fez que, em muitos sentidos, o governo fosse essencialmente apenas reativo e que o poder estatal local fosse deixado nas mãos de funcionários e oficiais que tinham grande autonomia tanto para interpretar as políticas de Estado como para perseguir seus interesses próprios. A natureza humana sendo o que é, nem sempre os interesses individuais coincidiam com os da Coroa. Vários funcionários - e outros recém-chegados - conquistaram fortunas na Irlanda, muitas vezes às custas do erário da Coroa ou com consequências danosas, a longo prazo, para as políticas de Estado. Mais ainda, o governo estava envolto em lutas internas e em facciosismos, em seu ápice na década de 1590, no assim chamado "segundo reinado de Elizabeth" (Guy, 1995). Na mesma época, os ingleses antigos (Old English) foram gradualmente excluídos das principais posições de poder. Apesar de sua constante lealdade e de afirmarem com orgulho sua anglicidade, eram suspeitos por causa de sua religião. Spenser, entre vários outros autores, acusou-os de terem degenerado e não serem mais ingleses. Assim, o período elisabetano foi de grande instabilidade na Irlanda. As antigas elites perdiam terras, poder e privilégios ao mesmo tempo em que arrivistas acumulavam fortunas. Naturalmente, isso gerou reações. Neste artigo, lidarei com uma delas, a Guerra dos Nove Anos. Focalizarei duas questões centrais. A primeira, a da responsabilidade de Elizabeth pela guerra: em que medida suas políticas e ações 
“causaram" a guerra? Será que poderia ter evitado a guerra se agisse de outra maneira? A segunda é o impacto de Elizabeth na condução da guerra propriamente dita.

\section{Elizabeth e a responsabilidade Pela Guerra dos Nove Anos}

Tratarei agora da responsabilidade de Elizabeth pela guerra. Esse é um tema que ainda não vi ser discutido. Por um lado, os historiadores ingleses tendem a encarar a Irlanda como de certa forma separada da entidade política inglesa e estranha a ela; como algo de que, quando se chega a abordar, se trata em seções finais dos trabalhos ou em trabalhos separados, sobre Irlanda e não Inglaterra. A maioria dos historiadores irlandeses tende a lidar com a Irlanda, considerar a intervenção inglesa como um dado e evitar a espinhosa questão da responsabilidade. Nem mesmo historiadores, como Bradshaw, que assumem uma perspectiva "nacionalista" se detiveram na questão. Não tenho muita ideia de por que assim seja, nem essa é uma indagação que perseguirei aqui. Nesta seção, buscarei antes apresentar alguns dos pontos que me parecem relevantes quanto à responsabilidade de Elizabeth pela guerra.

Como rainha da Inglaterra e da Irlanda Elizabeth deve, assim me parece, ser considerada a responsável última pela guerra. Não obstante a propaganda de tantos escritores Tudor, a Irlanda não era um país estrangeiro, não pertencia ao Novo Mundo. Estava sob a coroa inglesa desde o século XII, e boa parte de sua população se considerava inglesa. Mais ainda, o Ato do Reino da Irlanda de 1541 tornava todos os habitantes da ilha sujeitos da coroa e, teoricamente, dava-lhes direitos de súditos ingleses. Todavia, a questão da responsabilidade vai bem além disso. O que realmente importa é de que forma as ações da rainha contribuíram para a guerra. Suas políticas e decisões causaram a guerra - ou, talvez com maior precisão, em que medida Elizabeth foi fonte da guerra? Alternativamente, a guerra foi sobretudo resultado de outros fatores? Será que era de certa forma inevitável, parte intrínseca, por exemplo, de confronto entre um Estado em expansão e uma cultura marginal, nas franjas, um conflito entre civilização e atraso? Ou era algo em certa medida estrutural - uma das tristes consequências da guerra na Europa entre Espanha e Holanda/Inglaterra?

Para responder a essas questões, deter-me-ei na atitude geral de Elizabeth em relação à Irlanda, antes de tratar de aspectos mais específicos. Como já mencionei, Elizabeth não estava muito interessada na Irlanda, suas principais preocupações aí se restringindo a tentar não gastar dinheiro e a evitar que potências estrangeiras usassem o país para atacar a Inglaterra. Muito embora, 
olhando em retrospecto, o período elisabetano possa parecer de crescimento gradual e consistente do poder do Estado no país, esta não é uma visão com que concorde. É fato que o controle inglês sobre a Irlanda se expandiu consideravelmente durante o reino de Elizabeth, mas isso não resultou de uma política constante ou deliberada, antes pelo contrário. A política elisabetana em relação à Irlanda tendia a ter caráter reativo - o que aliás também foi a tônica na maioria dos reinados Tudor. Na verdade, em larga medida essa era a única opção disponível, já que a destruição do poder dos condes de Kildare e a imposição de vice-reis ingleses, junto ao progressivo afastamento da antiga elite dos ingleses antigos, criou uma situação política na Irlanda altamente dinâmica e volátil, separou a coroa de seus defensores "naturais" entre as elites nativas, deixando a política praticamente nas mãos da rainha e de seu Conselho Privado, cujo conhecimento da Irlanda era muito limitado e que também tendia a ser bastante hostil aos ingleses antigos e aos irlandeses gaélicos. Assim, a expansão do poder do governo foi em larga medida não intencional. Elizabeth aceitava a ideia de que a Irlanda precisava ser reformada (e provavelmente também civilizada) mas não se dispunha ao envolvimento em qualquer projeto mais substancial nesse sentido. Tampouco tentou rearranjar a estrutura administrativa do Estado, não obstante seus evidentes problemas. Talvez tivesse sido impossível levar a cabo a reformulação radical necessária, talvez estivesse além das habilidades de Elizabeth. Ao invés, ela como que deixou a rédea solta na Irlanda. Contudo, sua omissão em relação ao país e a tolerância para com as ações dos funcionários do governo, soldados e colonos no país, conjunto que em muito contribuiu para piorar a situação e conduzir às guerras e rebeliões, implicou que a rainha e seu governo fossem obrigados a reagir e a intervir. Isso teve como resultado uma expansão gradual e bastante caótica do poder do Estado, em larga medida dependente dos caprichos dos funcionários do governo. ${ }^{2}$ Junto a isso, havia uma intenção, um ideal, de reformar e civilizar o país, partilhada por vários grupos (à exceção da maioria gaélica, objeto para o qual a reforma se orientava). Percebiam-se divergências importantes sobre como levar a cabo essa reforma. Todavia, na década de 1590, os reformadores ingleses, antigos católicos, tinham sido alijados, e as concepções puritanas realçando a espada ao invés da palavra - haviam se tornado prevalentes.

Ao mesmo tempo, deve-se destacar que nem os irlandeses gaélicos nem os ingleses antigos eram meras marionetes que apenas reagiam às ações dos funcionários e colonos ingleses. Eles tinham, se é que posso recorrer ao jargão sociológico, agência própria. Podiam tomar suas decisões políticas, religiosas e ideológicas. $\mathrm{Na}$ verdade, em boa parte as medidas de Elizabeth é que eram 
reativas, tentando lidar com os resultados das ações dos vários atores sociais na Irlanda. Todavia, numa situação dinâmica e instável como essa, Elizabeth não demonstrou a virtù necessária. Talvez, como no caso da Holanda, se precisasse de um príncipe residente. $\mathrm{Ou}$, ao menos, um com compreensão e simpatia bem maiores por seus súditos ingleses antigos e irlandeses gaélicos. Isso provavelmente seria esperar demais de qualquer monarca europeu da época. Elizabeth é, contudo, a única entre seus contemporâneos a ser apresentada como modelo de virtudes, de modo que dela talvez isso se devesse esperar. ${ }^{3}$

É irônico que, em duas ilhas que mantiveram estreito contato por centenas de anos, o que pôde funcionar bem num país (entidade política, reino, ilha ou Estado - o leque para escolha do termo é bem amplo) com frequência tenha tido efeito oposto no outro. Enquanto os Tudor trouxeram estabilidade à Inglaterra com o encerramento da Guerra das Rosas, a restrição do poder das famílias nobres, a reforma das estruturas institucionais e a imposição de uma Igreja de Estado (por oposição à Igreja católica), suas tentativas de agir no mesmo sentido na Irlanda geraram consequências adversas, dando origem a um conflito generalizado e até a, pode-se pensar, uma espécie de instabilidade estrutural. Isso foi se tornando cada vez mais claro durante o reinado de Elizabeth, muito embora a ideia de que reformas conduzidas pelo Estado pudessem ser a causa de instabilidade certamente constituísse um anátema para os ingleses elisabetanos - uma categoria que, vale reparar aqui, cada vez mais se restringia aos "ingleses ingleses" (ou seja, que moravam na Inglaterra e se presumia serem protestantes), com exclusão dos ingleses antigos.

Após Henrique VIII esmagar a rebelião de Kildare na década de 1530, não houve mais vice-reis irlandeses, o que teve um efeito bastante desestabilizador no país, já que a rede de alianças que fora construída pelos condes de Kildare não foi substituída por nenhuma alternativa, provocando um aumento dos conflitos entre facções. O rompimento de Henrique VIII com Roma e a crescente influência reformista ou calvinista na Igreja de Estado levaram a uma exacerbação da situação. Elizabeth herdou um país complexo, dinâmico e instável. Ela também herdou uma abordagem institucional da Irlanda que se mostrava claramente deficiente e inadequada para lidar com o país - ou, pelo menos, aí manter a paz - e que era essencialmente reativa. A rainha pouco fez no sentido de alterar essa abordagem - em parte seguindo seus instintos e em parte acompanhando as restrições impostas pelo contexto de uma guerra europeia e de carência de recursos.

É interessante comparar a atitude de Elizabeth em relação à Irlanda com a de Filipe II face aos holandeses. ${ }^{4}$ Embora Filipe considerasse os holandeses 
heréticos e rebeldes, nunca os acusou de selvagens ou bárbaros. Nem, tanto quanto sei, quaisquer escritores espanhóis influentes, soldados ou funcionários defenderam a "eliminação" dos holandeses, ou se gabaram abertamente da quantidade de mulheres ou crianças holandesas mortas. A bem da verdade, isso não impede que tenha havido várias tentativas de "reformar" ou "civilizar" os gaélicos sem recorrer à coerção violenta ou a meios militares. Todavia, essas tentativas de um modo geral fracassaram e, em finais do século XVI, tinham basicamente sido abandonadas. A reforma agora, para usar uma expressão de Brendan Bradshaw, era com a espada e não com a palavra (Bradshaw, 1978).

Elizabeth, como já mencionei, herdara uma entidade política instável. A sua negligência em relação ao país exacerbou tal instabilidade. Isso também decorreu da atitude tolerante em relação às ações de vários de seus funcionários na Irlanda, à exclusão gradual da elite dos ingleses antigos de posições de privilégio que antes detinham no aparato estatal e ao saque de terras pelos colonos ingleses, a exemplo do empreendido por Peter Carew - com base em antigas reivindicações de terras, no mínimo duvidosas, há muito ocupadas por outros. Em função disso, Elizabeth foi forçada a intervir constantemente na Irlanda. Ainda assim, não obstante os contínuos esforços de pacificação da ilha (ou da derrota de rebeliões específicas) e a aparência de expansão do poder estatal daí decorrente, incluindo-se a plantation de Munster na década de 1580, os problemas do país, para desespero dos conselheiros do Privy Council, só davam impressão de piorar. Em grande medida isso se devia às contradições inerentes à inconsistência das políticas de Elizabeth em relação à Irlanda (e aos irlandeses gaélicos em particular). Se, por um lado, ela buscava pacificar determinados senhores e impor ordem e civilidade, por outro, tolerava comportamentos e políticas que solapavam a estabilidade do país.

Todavia, como também já referi, os irlandeses gaélicos - e os vários outros grupos na Irlanda - eram detentores de agência, eram todos participantes ativos da entidade política irlandesa. Eles contribuíam para a instabilidade geral, na sua perseguição de objetivos específicos, seus conflitos e alianças; e assim não deixam de carregar certa responsabilidade pela guerra. Cabe agora voltarmo-nos para Hugh O’Neill, que nisso teve papel de destaque.

No seu interessante livro sobre Shane O’Neill, Ciaran Brady defende que havia uma instabilidade intrínseca no condado dos O’Neill, em razão de seu tamanho e características geográficas mas, sobretudo, por causa da tensão entre a rica, apesar de militarmente vulnerável, Strabane e a mais pobre, embora mais poderosa e defensável, Dungannon. Isso teria dado origem a uma dinâmica agressiva no âmbito do senhorio que, de acordo com Brady, correspondia 
à "acceptance of the fact that if they were to survive, the O'Neills must also dominate” (Brady, 1996, p.9). Não obstante, embora o senhorio dos O’Neill fosse o domínio gaélico mais poderoso, mostrava-se incapaz de obter hegemonia sobre o Ulster. De certa forma, o condado, na busca por estabilidade, estava condenado a lutas sem fim na busca pela hegemonia, tarefa complicada pelos conflitos e disputas no seio do condado. A entrada de Hugh O’Neill nesse universo político dos O'Neill foi bem pouco auspiciosa. Tanto seu pai como seu irmão mais velho foram mortos na guerra civil dos O'Neill na década de 1550. Na verdade, Hugh O’Neill foi obrigado a procurar refúgio fora do condado - apesar de ter sido na Irlanda e não na Inglaterra, como vulgarmente se pensa. Quando retornou ao Ulster como barão de Dungannon, provavelmente em 1569, teve de contar com o apoio de tropas do governo. Apesar disso, nas três décadas seguintes conseguiu expandir seu poder e construir alianças até efetivamente realizar a antiga meta dos O'Neill de dominação do Ulster, ao mesmo tempo criando uma rede de conexões pessoais em outras regiões do país que mais tarde se provariam de grande utilidade.

É curioso observar a perspectiva oposta que O’Neill e Elizabeth tinham a respeito da ascensão dele ao poder. Elizabeth acreditava ser sua responsabilidade, ao passo que O'Neill considerava que tudo se devia a seus próprios esforços - a seu próprio "esgravatar". No final de 1597, o bispo de Meath, Thomas Jones, relatou a seguinte conversa com Hugh O’Neill, na qual teria tentado explicar-lhe que a rainha sempre havia sido justa no trato com ele:

To this he was willed to call to his remembrance how Her Majesty had dealt with him all that time, how from his cradle she had persevered him by her motherly care ... assigned all her forces to attend him for his defence, and at length had advanced him to this great honour. Hereunto he answered most ungratefully, that her majesty had given him nothing but what belonged unto him, and that he rather ascribed the things which he had gotten to his own scratching in the world than to Her Majesty's goodness; and also pleaded his great deserts, viz., that he had spent his blood, \&c. ${ }^{5}$

A outra questão que se deve colocar é se O’Neill e Elizabeth poderiam ter alcançado algum compromisso estável. Não é uma pergunta de resposta fácil. Com certeza Elizabeth não tinha interesse numa guerra generalizada na Irlanda, muito embora na década de 1590, em boa medida, os acontecimentos na Irlanda escapassem de seu controle direto. Durante o que Guy chama de "segundo reinado de Elizabeth", facções e a avançada idade da rainha cobravam seu preço 
no governo; e na Irlanda a situação era muito piorada. O vice-rei Fitzwilliam de certa forma condensa o que havia de errado com o Estado. Era considerado corrupto. A execução de Hugh Roe MacMahon e o sequestro de Hugh Roe O'Donnell minaram a confiança dos lordes gaélicos no Estado e ajudaram O’Neill a pôr de pé sua Confederação. Isso, por si, não seria suficiente para detonar a guerra ou para transformar uma rebelião localizada num conflito à escala do país. Foi preciso habilidade por parte de O’Neill e inépcia por parte de Elizabeth para que tal ocorresse. O’Neill construiu uma aliança de alcance provincial. No começo apenas queria o domínio dos O’Neill sobre o Ulster, há tanto almejado. Quase com certeza se teria satisfeito com o estatuto de Palatino. Todavia, isso foi complicado por uma série de razões - algumas das quais já se mencionou, como as facções no governo e os funcionários locais perseguirem objetivos próprios. Além disso, Elizabeth oscilava permanentemente nas ordens e conselhos que enviava a seus funcionários na Irlanda. Também tendia a evitar tomar decisões. Ela não queria uma guerra e não queria gastar dinheiro mas, ao mesmo tempo, relutava em oferecer termos generosos a O'Neill. Por exemplo, numa carta ao Conselho, escrita em outubro de 1594, na qual criticava os membros por não terem prendido O'Neill quando aparecera diante do Conselho em agosto, a rainha também os admoestava por deixarem O’Neill falar em trégua e em paz: "Besides, in the Earl's letters to Moore mention is made of truce and peace, which we disdain to hear in the mouth of a subject; so we hope you have not given him cause to speak thus" ${ }^{6} \mathrm{Na}$ mesma data, enviava ainda uma carta ao vice-rei criticando-o por não conseguir arquitetar um plano para capturar O’Neill, mostrando-se incapaz de seguir uma estratégia de "dividir e mandar" que fizesse o conde submeter-se:

We hold it strange that in all this space you have not used some underhand way to bring in the Earl; and we think that by setting division in his country, wherein full many there are which would be glad to be maintained against him, and by other sound means, he may be disabled and reduced to obedient conformity, which were more honourable to us and commendable in you than to be put to trouble for such a base person. ${ }^{7}$

$\mathrm{O}$ vice-rei, todavia, constantemente pedia à rainha e ao Conselho Privado que se decidissem por guerra ou paz, enquanto suplicava por suprimentos, dinheiro e homens, e alertava que O’Neill ameaçava o reino todo:

I find the Earl of Tirone's forces and means to be so strong, his late provision of munition so great, his friends and favourers, even in every place of the Pale, so 
many, and the malice extreme of the Jesuits and Seminaries possessing and incensing him so extreme, that unless Her Majesty will be pleased to resolve a speedy prevention, by supplies out of England, I see not what should let him to endanger the whole state. ${ }^{8}$

A rainha, todavia, relutava em escolher o curso a seguir, aparentando não querer nem guerra nem termos aceitáveis de paz (que basicamente teriam implicado perdão geral e concessão de poder palatino sobre o Ulster a O’Neill). $\mathrm{O}$ resultado foi um beco sem saída e o consequente derivar para uma guerra longa e muito cara. Mesmo assim, Elizabeth se recusava a escolher um caminho, apenas concordando com o envio de mais soldados para a Irlanda em novembro de 1594. Além disso, quando o juiz-mor da Irlanda foi enviado a Londres para discutir a situação com a rainha, ela não apenas se recusou a recebê-lo como ainda admoestou o Conselho em Dublin por ter mandado personagem tão importante e reclamou que O’Neill teria interesse na viagem de Gardiner. ${ }^{9}$

Nesse momento, Elizabeth parece ter deixado escapar a oportunidade de chegar a um acordo. É provável que nesses estágios iniciais da guerra algum tipo de paz pudesse ter sido estabelecido. Talvez não durasse - uma vez que a rainha teria de aceitar o que era inaceitável para ela, uma limitação de seu poder e um retorno ao status quo ante. Ela também teria tido de reformar seu governo na Irlanda, algo que talvez não fosse possível. Para além disso, há que se indagar se O’Neill teria respeitado uma paz a longo prazo. Novamente a resposta é difícil. O objetivo inicial de O’Neill era o domínio do Ulster, que conseguiu "à bruta". Também tornou o Ulster praticamente ingovernável mediante incursões rápidas, incêndios, assassinatos e outras formas de perturbação. Isso não impede que parecesse de um modo geral capaz de controlar suas forças quando queria. Outro ponto era confiança. O’Neill dispunha de vários contatos no seio do governo e tinha relações de amizade com vários senhores leais e funcionários - muito embora houvesse outros, com destaque para Bagenal, em relação a quem tinha profunda animosidade (ao passo que ainda outros, em especial os recém-chegados, por sua vez desenvolveriam profunda animosidade em relação a ele). Se utilizadas adequadamente, essas redes de amizade, parentesco e patronagem poderiam ter-se prestado a ancorar uma situação de paz. Todavia, tendiam a ir de encontro ao ethos do período tardio do governo de Elizabeth, dominado na Irlanda por indivíduos voltados para o aumento de suas próprias fortunas, que costumavam ser fortemente anticatólicos, consideravam os ingleses antigos como degenerados e desleais e 
preferiam, para voltar à ideia da frase de Brendan Bradshaw, usar "a espada" ao invés da "palavra" na reforma do Estado irlandês. Vários desses personagens acabaram por desempenhar papéis cada vez mais importantes no governo durante a guerra - e dominá-lo-iam após a guerra. Por fim, há que se considerar o papel da Espanha. Havia interesse na continuação da guerra, de modo que não resta dúvida que os espanhóis teriam tentado minar uma paz que se estabelecesse.

A Guerra dos Nove Anos foi bastante complexa. Não foi acionada por um evento específico, mas pela interação de diversos fatores e pelas ações de vários sujeitos. Embora Elizabeth não fosse a única responsável, seu papel de rainha a torna personagem de peso. Isso talvez possa ser mais adequadamente descrito como fracasso, omissão e até mesmo incompetência do governo. Elizabeth, em função de sua negligência diante do país, sua atitude oscilante e sua tolerância para com as facções, a corrupção e a autonomia dos funcionários, criou as condições que levaram à guerra. Sem dúvida, ela não tinha controle direto sobre parte dos acontecimentos mas muitas vezes estes foram consequências, não intencionais, de suas decisões ou de suas políticas em relação à Irlanda.

Um aspecto que vale a pena considerar é que Elizabeth era uma monarca ausente na Irlanda, como era comum na Europa dos séculos XVI e XVII. Alguns monarcas de reinos compostos foram bem-sucedidos; a maioria não o foi. Um dos problemas enfrentados era a ausência de uma corte, um ponto para contato do monarca com as elites locais. $\mathrm{Na}$ corte, estas tinham acesso ao monarca e aos privilégios que ele outorgava. $\mathrm{O}$ monarca, por seu turno, forjava alianças, construía bases de sustentação, obtinha informações e experiência. A política elisabetana em relação à Irlanda, em que pesem as tentativas de alguns indivíduos isolados, foi severamente estorvada pela distância entre a Irlanda e Londres (uma distância em vários sentidos, além do meramente geográfico), bem como pelo preconceito e pela ignorância. Não dispunham de mapas, os irlandeses gaélicos eram vistos como bárbaros, nômades ou como citas; malignos até. É fato que os ingleses antigos com frequência mostravam preconceito em relação a seus vizinhos gaélicos e certamente não viram nenhum problema em sua representação como bárbaros - apesar de eles próprios também virem a ser marginalizados. Esse preconceito, bem como o fato de não se levar em conta a contribuição vital dos senhores leais, atrapalhou os esforços de guerra elisabetanos.

Nesse sentido, é interessante tecer uma comparação com outros reinos compostos. A comparação mais óbvia é com a Revolta Holandesa. Tem vários paralelos com a Guerra dos Nove Anos: diferenças religiosas, um monarca 
ausente, legislação impopular etc. Todavia, seria também útil considerar por que nenhum dos outros reinos de Felipe II se rebelou - tais como a Catalunha e Portugal, que só o fizeram, ambos, em 1640. Deve-se ainda pensar que a Espanha manteve controle do sul dos Países Baixos. Aqui, a indicação do arquiduque Alberto e de sua mulher, a Infanta Isabella, como cossoberanos implicou uma corte e uma fonte de liderança e de políticas que teve papel destacado no fracasso da revolta no sul dos Países Baixos. Outra comparação, que tanto quanto sei ainda não foi feita em detalhe, é com Carlos I. Há paralelos entre o tratamento dado por Elizabeth à Irlanda e o dado por Carlos I à Escócia e à Irlanda, relacionados a problemas derivados de monarcas ausentes e em associação com dificuldades religiosas e conflitos com as elites locais.

\section{Travando A GUERRA}

Trataremos agora da segunda questão, o impacto de Elizabeth na condução da guerra. Pelo exposto na seção anterior, duas características do comportamento da rainha parecem ter tido efeitos diretos: sua relutância em "abrir a bolsa” e sua indecisão. Durante a guerra Elizabeth permaneceu sempre preocupada com a questão financeira. Quando Mountjoy foi nomeado, ele recebeu ordens de reduzir o tamanho do exército e controlar os gastos:

Has resolved for the present to maintain an army of 12,000 foot and 1,200 horse, and has appointed such sums of money to be sent to Ireland, as shall be necessary to defray the expenses of other officers and servitors. No addition is to be made to the army, except for some notorious peril to the kingdom, which is to be notified with all expedition. ${ }^{10}$

Mesmo no final, a rainha reclamava com Mountjoy sobre os "infindos custos" da guerra:

as you can well consider of what importance it is to Us to ease our Kingdom of those great or rather infinite charges, which We have thus long sustained, which stil continuing in that height, would take away the true feeling of our Victories, We have thought good for Us to lacke a great part of their reduction, as to be driven to that charge in keeping them, which our Crowne of England cannot indure, without the extreme diminution of the greatnes and felicity thereof, and alienation of Our peoples minds from Us, considering that for these only rebellions in Ireland, We have bin forced to part with many of Our ancient posses- 
sions, which are part of Our flowers of our Crowne, and to draw from our subjects (a thing contrary to Our nature) those great payments, which (but for the hope they had, that the same should not serve to work their future ease and respiration) they would not so willingly have borne, nor We so justly could have imposed upon them. ${ }^{11}$

Essa preocupação com despesas provavelmente era comum a quase todos os monarcas europeus da época. Tanto Filipe II como Filipe III de Espanha foram forçados a declarar falência em mais de uma ocasião, ao passo que, à exceção da Holanda, todos os demais estados precisaram lidar com carência crônica de fundos. Isso era particularmente verdadeiro quando guerras estavam envolvidas, as quais eram muito caras, como Elizabeth - junto aos demais monarcas - vivia se dando conta.

As oscilações frequentes de opinião de Elizabeth causaram vários prejuízos. Como referido no final da seção anterior, ao longo de 1594 Elizabeth não conseguia se decidir sobre como lidar com Hugh O’Neill. Em função disso, perdeu-se tempo e dinheiro, bem como oportunidades. Até mesmo quando se tomou a decisão de proclamar O’Neill traidor e empreender ação militar contra ele, ainda havia constantes problemas com suprimentos, fundos e homens. A organização de linhas de suprimento levava tempo - apesar de, perto do fim da guerra, o sistema funcionar razoavelmente a contento, ainda assim se mostrava bastante frágil e bastante inferior à "Estrada Espanhola" usada para abastecer as tropas na Holanda. A relutância de Elizabeth em partir para uma guerra total, que seria cara, como sempre a alertavam, associava-se à sua vontade de alcançar a paz em termos que considerasse honrosos - e não em termos que refletissem a situação existente. Assim é que se vê Norris, em abril de 1597, envolvido em negociações sem resultados com O'Neill, queixar-se da "rigidez" de suas "instruções"; também afirmando que "the State will not yield any advice to alter any part thereof". ${ }^{12}$ A inconstância de Elizabeth como que impunha um certo tipo de paralisia ao governo, que não era capaz nem de entrar adequadamente na guerra nem de alcançar uma paz sustentável. ${ }^{13}$ Isso também permitiu a O’Neill tomar a iniciativa e expandir a sua confederação, que se estendia a Connaught e ao Ulster, bem como fortalecer os laços com a Espanha. Esses dois aspectos aumentaram a volatilidade da situação e enfraqueceram a possibilidade de se encontrar uma solução não militar.

Ironicamente, a indecisão de Elizabeth quanto à estratégia a seguir levou O’Neill a tomar a iniciativa e a forçou a fazer concessões que de início não queria. Por exemplo, em setembro de 1595, a rainha mandou que se 
impusessem a O’Neill termos severos - após ser perdoado, O’Neill teria de rogar por sua vida e posses e seria despojado do título de conde:

Let him know that, besides his life, he has forfeited his whole estate, so as whatsoever he may have hereafter is to come to him anew from us. He must leave all combinations with all disobedient subjects and all strangers. If he consent to this, you may tell him you will procure that he shall be restored to his former estate of the barony of Dungannon, as granted to his father, Matthew, when Con O'Neale, his grandfather, was made Earl by King Henry VIII; the Earldom to remain in our disposition until he deserve to be restored to the same. It is to be considered what lands might be restored to him. ${ }^{14}$

Poucos meses mais tarde, diante da perspectiva de uma iminente invasão espanhola, Elizabeth foi forçada a suavizar bastante seus termos, dizendo ao vice-rei Russell, a Norris e outros que podiam oferecer livre perdão a O’Neill e outros senhores, que deviam "make all the conditions as honourable as you may, and especially that our revenue in Monoghan be still answered to us". ${ }^{15}$

Além disso, a recusa em financiar a guerra adequadamente e em aceitar os termos de O’Neill via-se agravada por sérios conflitos no âmbito do governo irlandês. Entre 1595 e 1597 o governo na Irlanda foi muito enfraquecido pela divisão de poder na Irlanda entre o vice-rei Russell e Sir John Norris, nomeado comandante dos exércitos. A antipatia e a discórdia entre eles eram exacerbadas pelo fato de pertencerem a facções opostas da corte - Russell pertencia à de Essex, ao passo que Norris era parte da de Burghley. A disputa entre esses dois funcionários comprometeu seriamente o esforço de guerra do governo nesses anos. Cada um adotava posições diferentes diante de O'Neill, o vice-rei defendendo que se assumisse uma postura dura diante dos rebeldes em contraste com a atitude de Norris, mais favorável a um acordo de paz:

There was in many things no small emulation betweene the Lord Deputie and him, and no lesse in Tyrones particular. The Lord Deputies seemed to the Lord Generall, to be unequall and too sharpe against Tyrone, with whom he wished no treaty of Peace to bee held, (which he wisely did, having experienced his false subtilties, and knowing that he sought delaies, onely till hee could have aide from Spaine.) But the Lord Generall (whether it were in emulation of the Lord Deputy, or in his favour and love to Tyrone) was willing to reclaime him by a Gentle course (which that crafty Fox could well nourish in him.) And it seemes some part of the Winter passed, while this project was negotiated betweene them. (Moryson, 1908, v.iii, p.198) 
Muito embora essa divisão fosse fruto da decisão própria da rainha - e, em certa medida, da sua crescente falta de habilidade em jogar as diferentes facções de sua corte umas contra as outras com sucesso -, ela recusou-se a assumir qualquer responsabilidade, jogando a culpa exclusivamente sobre o governo na Irlanda:

And considering the many disasters happened in that realm, whereof we mind not by this our letter to express our opinion in whose defaults amongst you of our Council the same happened, being such and so notorious as it is but too apparent to the whole world that never any realm was worse governed by all our ministers from the highest to the lowest. ${ }^{16}$

Todavia, a rainha era incapaz de parar as contendas e brigas. Mesmo que Norris tivesse menos responsabilidade do que o vice-rei, ele enviou uma enxurrada de missivas a Cecil queixando-se de Russell e acusando-o, entre outras coisas, de desobedecer à rainha:

This much I protest to your Honour, that I know the Lord Deputy will not spare to do anything that might bring me in disgrace and remove me from troubling his conscience here, fearing much his own continuance in this his government whereof he hath taken so good a taste he will try the whole credit of all his friends before he will leave it. ${ }^{17}$

Uma situação semelhante pode ser encontrada poucos anos depois. Em 1600 Essex constantemente se queixava de seus inimigos em Londres. Na verdade, ele começou a se queixar antes mesmo de deixar a Inglaterra:

For myself, if things succeed ill in my charge, I am like to be martyr for her. But as, your Lordships have many times heard me say, it had been better for her service to have sent a man favoured by her, who should not have had these crosses and discouragements, which I shall ever suffer ... yet to enable me to reduce that rebellious kingdom of Ireland to obedience, lies in Her Majesty; for, if I have not inward comfort, and outward demonstration of Her Majesty's favour, I am defeated in England. ${ }^{18}$

Durante o período que permaneceu na Irlanda, apesar das garantias recebidas do Conselho Privado, as suas reclamações só aumentaram: 
But, as I ever said, I ever must say: I provided for this service a plastron and not a curate; that is, I am armed on the breast, but not on the back. I could not fight so well as we would in a good. Howbeit, if the rebels shall once come to know that I am wounded in the back, not lightly, but to the heart (as, I fear me, they have too true and too quick advertisements of this kind), then what will be their pride and the state's hazard, your lordships in your wisdoms man easily discern. ${ }^{19}$

Embora as queixas de Essex possam ter sido exageradas - e com certeza constituíssem uma maneira inadequada de lidar com o problema -, continham provavelmente certa parcela de verdade:

Neither in the whole course of my life hitherto, nor in respect of the success of my government here, nor or my years, that are now almost forty years old, I deserve so little belief or reputation as to find myself believed in nothing concerning this estate or my own particular while I am here, and every idle projector, or poor false discontented informer, to prevail in your judgements against me ... My own heart and the heart of my endeavours are broken, and therefore, Sir, I desire you, even for humanity's sake, to deliver me of this burden, which you know how violently it was thrust upon me; and my own conscience knoweth how much I am wronged in it. ${ }^{20}$

Vale a pena ainda observar as instruções de Elizabeth a Essex e a Mountjoy, na medida em que ilustram com clareza como Elizabeth tentou moldar a estratégia da guerra. Também ilustram o quão pouco se sabia sobre as condições das forças inglesas na Irlanda, faltando informações básicas como o tamanho e a situação atuais do exército. Isso aponta para o fracasso nas tentativas de reformar o Estado e reduzir a corrupção. É nesse sentido que Essex recebeu ordens de descobrir o tamanho e a situação do exército já que se presumia que os certificados de revista de tropas estivessem completamente errados. Mais, Essex recebeu instruções de enviar a cada dois meses um "orçamento" dos "encargos" da rainha com o exército e recibos para o montante total enviado da Inglaterra e para quaisquer outras fontes de renda da Irlanda. Para além disso, também lhe foi dito que poupasse o quanto fosse possível e não desperdiçasse "ordnance, powder, and munition". ${ }^{21}$

A ordem inicial que Mountjoy recebeu foi de reduzir o exército para 12 mil homens, um número que, após muito rogo, subiu para 14 mil. Devia ainda reformar o exército e frear a corrupção, em especial no tocante aos certificados de revista de tropas: 
first and above all things, we do hold it for certain, that no Prince can be more deceived, or kingdom more endangered, than we are in the matter of musters, which we cannot impute to any one thing more than to the bad choice of Captains; whereof although we know we have many that are valiant and well-deserving, yet divers are so needy and ill-disposed, as they do nothing but seek to deceive or corrupt those that are appointed Commissioners of our musters. ${ }^{22}$

Mountjoy recebeu instruções mais detalhadas sobre como conduzir a guerra, em comparação com Essex. Este último recebeu "poderes extraordinários” para conceder indultos, inclusive ao próprio O’Neill - que tinha permissão de perdoar "upon such conditions as you shall find good and necessary for our honour and safety of that kingdom". ${ }^{23}$ Essex não recebeu instruções militares detalhadas por causa de sua posição e de sua proximidade com a rainha: "Although it is not needful for us to instruct you, 'to whom all particulars are better known (in respect of your inwardness in counsel and favour with us) than any other that hath gone before you,' yet we think it not amiss to prescribe such things as are necessary for you to observe". ${ }^{24}$ Já a Mountjoy, em contraste, foram passadas instruções bem específicas. Foi-lhe dito que deveria construir guarnições de onde se pudessem fazer surtidas e atacar os rebeldes:

yet may you see by all men's opinions that it is plainly confessed that there is no course to be taken but by plantation of garrisons in the heart of the countries of the capital rebels; where you see we have resolved to make them of such condition as they shall not only serve for diversion by making good the place of their residence, but also to be able to sally out, and make continual incursions into their countries. For which purposes, seeing you perceive that we do sort our garrisons both for numbers and places to make a mixed war, we doubt not but you will labour by all means possible to make the right use and application of the same. ${ }^{25}$

Podia, ainda, ser leniente com os rebeldes do Ulster, embora não com os de Munster. Por fim, deveria tentar impor condições duras a O’Neill, embora, se necessário, pudesse aceitar um mero ato de submissão:

But if his overtures do continue, and that you think any good opportunity may be lost in sending to us, then if he will simply submit himself to our mercy, we can be content you do receive him. But of this liberty given you, we would have you keep secret, for we could better like that by all means you should notify to the world, that you will only receive all others that will leave him. ${ }^{26}$ 
Afora o envio de instruções detalhadas aos vice-reis quando empossados, ou durante negociações de tréguas, a rainha tendia a não interferir diretamente na condução rotineira da guerra. Como em geral na sua política em relação à Irlanda, satisfazia-se com deixar seus funcionários conduzir a guerra. Em certa medida isso era conveniente já que as comunicações e a inteligência deixavam muito a desejar e estavam sujeitas aos caprichos do tempo. Nem por isso, como já destaquei, a rainha hesitava em criticar seus funcionários na Irlanda, em especial quando achava que sua honra fora manchada ou que se estava desperdiçando dinheiro. Também elogiava seus funcionários (embora muito menos). Numa dessas cartas, num dos raríssimos momentos de jovialidade mostrados durante a guerra, a rainha referiu-se a si própria como "Mistress Kitchenmaid" [Dona Criada de Cozinha]:

Mistress Kitchenmaid - I had not thought that precedency had been ever in question, but among the higher and greater sort; but now I find by good proof that some of more dignity and greater calling may by good desert and faithful care give the upper hand to one of your faculty, that with your frying-pan and other kitchen stuff have brought to their last home more rebels, and passed greater break-neck places, than those that promised more and did less ... Your Sovereign that dearly regards you. ${ }^{27}$

Ao mesmo tempo, a rainha parecia esperar adulações e gratidão por parte de seus funcionários na Irlanda. Por exemplo, em julho de 1601, durante a campanha de Blackwater, Mountjoy convenceu-se de ter perdido as boas graças de Elizabeth quando um de seus funcionários voltou após uma estada na corte. Todavia, de acordo com o funcionário em questão, o que tinha desagradado Elizabeth era Mountjoy não lhe ter escrito agradecendo seus favores e bondade: "she blamed him that, having received letters written by so royal hands, he had been so careless to return answer or thanks, till I returned again". ${ }^{28}$

\section{Conclusão: Elizabeth e a Guerra dos Nove Anos}

Neste artigo lidei com duas questões principais, a responsabilidade de Elizabeth pela Guerra dos Nove Anos e seu impacto na condução da guerra propriamente dita. Os dois temas interligam-se diretamente à negligência com que Elizabeth tratou a Irlanda. A rainha queria ter de lidar com a Irlanda o mínimo possível, muito mais reagindo ao que acontecia do que ativamente formulando políticas. Isso não impede que estivesse disposta a tolerar - e por 
vezes apoiasse - as ações de funcionários e colonos que frequentemente iam no sentido de romper o tecido social do país, gerar agitações e conduzir a revoltas, o que implicava que Elizabeth fosse obrigada tanto a intervir como a alocar dinheiro - e o que também impedia quaisquer projetos de reforma pacífica do país. Ao limitar sua política a pouco mais do que reação aos acontecimentos, junto a uma vaga aspiração de reforma, a rainha abandonou qualquer possibilidade de manter controle sobre a Irlanda. Teve também como resultado conduzi-la a uma guerra de vastas proporções, que só foi vencida a um grande custo.

Numa época de reinos compostos, quando a presença física do monarca - em particular da corte, um ponto definido de contato e comunicação entre o monarca e as elites locais, no qual as elites tinham acesso à pessoa do monarca e o governo obtinha informações e, por vezes, aliados - era de grande significado, monarcas ausentes enfrentavam mais problemas. Se não se lidasse com eles de forma adequada, esses problemas facilmente se transformavam em revoltas - a grande maioria das vezes mais contra os representantes, os "malvados conselheiros", do que diretamente contra o monarca. Quando as antigas elites eram substituídas por novas e/ou quando estavam envolvidas questões religiosas, tais dificuldades podiam ser agravadas. O exemplo mais notável é a revolta dos holandeses contra Filipe II; os problemas de Carlos I com a Escócia e a Irlanda podem ser considerados sob a mesma perspectiva. As dificuldades de Elizabeth com a Irlanda devem também, assim penso, ser vistas nessa linha. Pode-se considerar Elizabeth responsável pela Guerra dos Nove Anos na medida em que permitiu que ganhassem curso as condições que levaram à guerra, bem como por ela ter deixado escapar oportunidades de evitá-la, encerrá-la antes e/ou prevenir que uma revolta local se transformasse numa guerra generalizada no país. Evidentemente a rainha esteve longe de ser a responsável exclusiva pela guerra ou mesmo sua causadora direta. Porém, ela era a rainha - e uma rainha considerada por muitos como modelo de virtudes - e deve, pois, ser-lhe imputada parcela significativa da "culpa".

No tocante à condução da guerra pela rainha, aqui ela também adotou uma perspectiva de "deixar correr". Ela era, todavia, responsável pela escolha do vice-rei na Irlanda e de outros altos funcionários. Por vezes Elizabeth também procurava esboçar linhas estratégicas para a guerra - embora junto ao Conselho Privado. Provavelmente seu maior efeito esteve ligado à questão financeira. A rainha estava constantemente preocupada com dinheiro e com a redução dos custos. Isso implicou que, durante os primeiros anos da guerra, oscilasse entre uma solução militar e negociações. Relutava em - ou talvez não 
tivesse como - financiar adequadamente a guerra, apesar dos alertas que recebeu do dano que assim se causaria. Mais, a constante falta de fundos teve efeitos adversos tanto na eficiência como na situação do exército. Por vários anos, seguia-se um ciclo vicioso. Tentava-se derrotar O’Neill militarmente. Isso falhava por causa da falta de homens e de suprimentos - bem como pela incompreensão da natureza da guerra e da tradição gaélica de luta. Assim, havia que voltar à mesa de negociações; e as deficiências no exército não eram sanadas nesses períodos de paz. Quando as negociações eram interrompidas, fosse por O’Neill subir suas apostas ou por a rainha recusar-se a aceitar os termos exigidos por O’Neill, havia que retornar à força militar, novamente alcançando os mesmos resultados insatisfatórios. Dificuldades financeiras e a falta de uma constância política também implicaram que os necessários habilidade, experiência e processos ligados a levantamento, transporte, suprimento e paga de soldados - em suma, à condução da guerra - demorassem mais tempo a se desenvolver e institucionalizar, em contraste com a Espanha. Além disso, a obsessão da rainha com dinheiro e sua oscilação fizeram que no longo prazo a guerra na Irlanda se tornasse muito mais séria - talvez até ameaçando o domínio inglês na Irlanda - e acabasse por custar muito mais a Elizabeth. Apesar de vários alertas de funcionários na Irlanda, logo desde o início da guerra, sobre os problemas que a falta de dinheiro implicaria, a situação miserável de suas tropas na Irlanda e a ameaça a esse reino, Elizabeth optou por ignorar tais conselhos, tentando obter uma paz honrosa na Irlanda mas sem lidar com as causas do "problema irlandês". Como consequência, a rainha cometeu um erro duplo. Em primeiro lugar, ao optar seguidamente pela solução mais barata e ao não financiar adequadamente seu exército na Irlanda - e adotando uma política para o país que era sobretudo reativa -, condenou-se a uma guerra que seria cada vez mais cara e mais jogada nos termos de O'Neill, cujo objetivo não era lutar ou vencer batalhas decisivas mas antes sobreviver e preservar seu poder. Isso se ligava à inabilidade da rainha em reformar o governo na Irlanda, eliminar a corrupção e de fato descobrir para onde o dinheiro escoava, bem como ao exercício do controle efetivo das ações do seu governo e dos funcionários na Irlanda. As ações dos vice-reis e de vários outros funcionários solaparam boa parte das políticas da própria Elizabeth e foram causa direta da guerra; Norris, por exemplo, queixou-se, em várias ocasiões, de que o vice-rei Russell desobedecia à rainha e minava seus esforços de paz.

A Guerra dos Nove Anos foi um dos maiores desafios que Elizabeth enfrentou durante o seu reinado. Apesar de em última análise ter saído vitoriosa, essa não era uma conclusão inevitável da guerra. Na verdade, o resultado 
poderia ter sido radicalmente diferente. Além disso, a vitória de Elizabeth teve um preço muito elevado. O custo maior esteve representado nos que morreram durante a guerra, irlandeses gaélicos, antigos ingleses, escoceses e ingleses; mas também praticamente levou Elizabeth à falência. Além disso, a vitória de Elizabeth teve outra implicação - algo radical e que, embora oferecesse uma miríade de novas oportunidades, também representava um preço complicado, longe de evidente à época: a conclusão da conquista da Irlanda. Pela primeira vez toda a ilha passou a estar sujeita ao domínio inglês. Apesar das enormes transformações que ocorreriam no país nos anos seguintes associadas a essa conquista, a entidade política irlandesa não deixaria de continuar a mostrar-se, muitas e muitas vezes, fonte de dificuldades para os monarcas ingleses.

\section{REFERÊNCIAS}

BRADSHAW, Brendan. Sword, Word and Strategy in the Reformation in Ireland. Historical Journal, v.3, n.21, 1978.

BRADY, Ciaran. Shane O'Neill. Dundalk: Dundalgan Press, Historical Association of Ireland, 1996.

GUY, John. Introduction, the 1590s: the second reign of Elizabeth I?. In:

The Reign of Elizabeth I: Court and culture in the last decade, Cambridge: Cambridge University Press, 1995.

MORYSON, Fynes. An Itinerary Containing his Ten Yeeres Travell through the Twelve Dominions of Germany, Bohmerland, Sweitzerland, Netherland, Denmarke, Poland, Italy, Turky, France, England, Scotland and Ireland. (3v.). Glasgow: James MacLehose and Sons; University of Glasgow, 1908.

WALKER, Julia M. (Ed.) Dissing Elizabeth: negative representations of Gloriana. Durham, NC: Duke University Press, 1998.

\section{NOTAS}

${ }^{1} \mathrm{O}$ artigo foi redigido no âmbito da pesquisa de pós-doutorado intitulada "Guerra, formação do Estado e Identidade Nacional nas Franjas do Mundo Atlântico" realizada com bolsa da Faperj.

${ }^{2} \mathrm{~A}$ reforma de Monaghan pelo vice-rei Fitzwilliam, envolvendo a condenação à morte de um senhor importante, é um bom exemplo.

${ }^{3}$ Outra questão que emerge aqui é que muito embora as atrocidades espanholas (e portuguesas) no Novo Mundo sejam irrefutáveis, apareceram defensores dos povos nativos, com destaque para Bartolomé de las Casas, em relação à Espanha, e os jesuítas, como Padre 
António Vieira, no tocante a Portugal. Não há nenhum equivalente inglês se referindo à Irlanda. Ao invés disso, o que se tem é uma produção bastante significativa de textos pedindo o extermínio ou destruição dos irlandeses gaélicos e, embora em menor grau, dos ingleses antigos.

${ }^{4}$ Também seria interessante comparar a historiografia da rebelião holandesa com a das questões de Elizabeth na Irlanda, em particular diante dos irlandeses gaélicos. Embora Filipe II costume ser criticado por excesso de fanatismo e rigor no seu tratamento dos rebeldes holandeses, ele (e seus sucessores) disseram não à hipótese de abrir diques para inundar a Holanda. Já Elizabeth recebeu relativamente poucas críticas pelo tratamento, a maior parte das vezes terrível, dado aos irlandeses gaélicos por seus generais. Chichester, um completo parvenu fanfarrão - e futuro vice-rei - gabava-se abertamente das mortes de mulheres e crianças, ao passo que escritores como Spenser e Moryson se compraziam em detalhar graficamente os horrores promovidos por seus superiores.

${ }^{5}$ Thomas Jones, Bispo de Meath, a Burghley, Dublin, 28 dez. 1597, CSPI, July 1596-Dec. 1597, p.484; itálico acrescentado.

${ }^{6}$ A Rainha ao Vice-Rei e Conselho, Richmond, 31 out. 1594, Carew, 1589-1600, p.100.

${ }^{7}$ A Rainha ao Vice-Rei, Richmond, 31 out. 1594, Carew, 1589-1600, p.101.

${ }^{8}$ Vice-Rei a Burghley, Dublin Castle, 8 nov. 1594, CSPI, Oct. 1592-June 1596, p.281.

${ }^{9}$ A Rainha ao Vice-Rei e ao Conselho, Richmond, 31 out. 1594, Carew, 1589-1600, p.100.

10 "Instruções para Lorde Mountjoy", jan. 1600, CSPI, Apr. 1599-Feb.1600, p.441.

${ }^{11}$ A Rainha a Mountjoy, Richmond, 9.out.1602, apud MORYSON, 1908, v.iii, p.225.

${ }^{12}$ O presidente da Província, Sir John Norreys, a Sir Robert Cecil, Drogheda, 21 abr. 1597, CSPI, July 1596-Dec. 1597, p.274.

${ }^{13}$ Essa paralisia e flutuação custaram caro em termos de funcionários governamentais. Moryson, por exemplo, afirma que Norris morreu de coração partido pelo fracasso em conseguir um tratado de paz, pelos revezes militares e pela indicação de um novo vice-rei (MORYSON, 1908, v.iii. p.206-207).

${ }^{14}$ A Rainha a Sir William Russell, Vice-Rei, Nonesuche. 28 set. 1595, Carew, 1589-1600, p.124.

${ }^{15}$ A Rainha a Sir William Russell, Sir John Norries, Sir Harry Wallopp e Sir Geffrey Fenton. Richmond, 8 jan. 1596, Carew 1589-1600, p.131. Apesar disso, depois que uma espécie de tratado fora obtido conforme estas ordens da Rainha, Elizabeth recusou - como já comentei - encontrar-se com o juiz-mor Gardiner que tinha sido envido pelo Conselho irlandês a Londres para relatar o andamento das negociações por, entre outras razões, terem sido simpáticos demais com O'Neill (Sir Rob. Cecil ao Vice-Rei, a Corte em Richmond, 9 mar. 1596, CSPI, Oct. 1592-June 1596, p.488).

${ }^{16}$ Rainha Elizabeth a Sir William Russell, Vice-Rei e Conselho, Whitehall, 18 abr. 1597, CSPI, July 1596-Dec. 1597, p.266. 
${ }^{17}$ Sir J. Norreys a Cecil, Dublin, 23 mar. 1596, CSPI, Oct. 1592-June 1596, p.501-502.

${ }^{18}$ O Conde de Essex ao Conselho Privado, Hilbree, 5 abr. 1599, CSPI, April 1599-Feb. 1600, p.5.

${ }^{19}$ O Conde de Essex ao Conselho Privado, The Camp, $1^{\circ}$ jul. 1599, CSPI, Apr. 1599-Feb. 1600, p.76-77.

${ }^{20}$ Vice-Rei Mountjoy a Sir Robert Cecil, 31 ago. 1600, CSPI, Mar.-Oct. 1600, p.397.

21 "Instructions for our Cousin and Councillor Robert, Earl Essex, Earl Marshal of England \&c, Lieutenant and Governor General of our kingdom of Ireland”, Richmond, 25 mar. 1599, Carew, 1589-1600, p.294.

22 "Instruções a Lorde Mountjoy", jan. 1600, CSPI, Apr. 1599-Feb. 1600, p.441-442. Mountjoy também foi informado de que o governo não fazia ideia da situação efetiva do exército: "Touching the estate of the army, in which resteth our chief confidence, all the other parts of the realm being universally disjoined and altered, we cannot at this time deliver to his Lordship a perfect list thereof ... Only we understand by many private advertisements out of those remote provinces, that the companies there are weak in numbers, not answerable to that they ought to be;" (O Vice-Rei Mountjoy e o Conselho ao Conselho Privado, Dublin, $1^{\circ}$ mar. 1600, CSPI, Mar.-Oct. 1600, p.2).

23 "Instruções a nosso primo Conselheiro Robert, Conde de Essex, Conde Marechal da Inglaterra \&c, Vice-Rei e Governador Geral de nosso reino da Irlanda”, Richmond, 25 mar. 1599, Carew, 1589-1600, p.295.

${ }^{24}$ Ibidem, p.294.

25 "Instruções para Lorde Mountjoy", jan. 1600, CSPI, Apr. 1599-Feb. 1600, p.442.

${ }^{26}$ Ibidem, p.444-445.

${ }^{27}$ A Rainha ao Vice-Rei Mountjoy, Carew, 1589-1600, p.481.

${ }^{28}$ Sir Oliver St. John a Sir Robert Cecil, Blackwater, 17 jul. 1601, CSPI, Nov. 1600-July 1601, p.433-434. A Rainha parecia ter preferência por cartas de ridícula e obnóxia bajulação como a enviada por Carew: “To my unspeakable joy I have received your Majesty's letters signed with your royal hand, and blessed with an extraordinary addition to the same, which although it cannot increase my faith and zeal in your Majesty's service which from my cradle (I thank God for it) was ingraffed in my heart, yet if infinitely multiples my comforts in the same; and wherein my endeavours and poor merits shall appear to be short of inestimable favours, my never dying prayers for your Majesty's eternal prosperity shall never fail to the last day of life. But when I compare the felicities which other men enjoy with my unfortunate destiny to be deprived from the sight of your royal person which my heart with all loyal affection (inferior to none) evermore attends, I live like one lost to himself." (Sir G. Carew à Rainha, Cork, 3 jun. 1601, Carew, 1601-1603, p.74-75).

Artigo recebido em 31 de maio de 2012. Aprovado em 22 de outubro de 2014. 